\title{
OPTIMIZATION OF "GLUCOSE ${ }^{11}$ C" PHARMACEUTICAL PRODUCTION ON THE BEAM OF ELECTRON ACCELERATOR
}

\author{
I.S. Guk, R.N. Dronov, O.S. Deiev, B.I. Shramenko \\ National Science Center "Kharkov Institute of Physics and Technology", Kharkiv, Ukraine \\ E-mail: guk@kipt.kharkov.ua
}

The process of "Glucose ${ }^{11} \mathrm{C}^{\prime \prime}$ pharmaceutical production by means of a photonuclear reaction ${ }^{12} \mathrm{C}(\gamma, \mathrm{n}){ }^{11} \mathrm{C}$ is considered. The parameters of bremsstrahlung and electron beam scattered in the converter are investigated and optimized. It is proposed to use a constant-field magnet to remove electrons from the photon beam. A magnet design is proposed that allows obtaining a field of $0.5 \mathrm{~T}$ in a gap of $25 \mathrm{~mm}$. The production of the ${ }^{11} \mathrm{C}$ isotope in the glucose target was estimated.

PACS: 07.05.Tr, 41.50.+h; 41.75.Fr; 78.70 En

\section{INTRODUCTION}

Positron emission tomography (PET) is one of the two most common diagnostic techniques in nuclear medicine, based on the use of isotopes that emit positrons because of nuclear transformations [1]. The isotopes recommended for use in PET diagnostics [2,3], radiopharmaceuticals containing ${ }^{15} \mathrm{O}$ (half-life $2.04 \mathrm{~min}$ ), ${ }^{13} \mathrm{~N}$ (9.96 min), ${ }^{11} \mathrm{C}(20.4 \mathrm{~min}),{ }^{18} \mathrm{~F}(110 \mathrm{~min})$ are mainly used. ${ }^{18} \mathrm{~F}$ isotope has optimal characteristics for use in PET: long half-life and lowest $\beta+$-radiation energy. Currently, the most commonly used pharmaceutical in clinical PET scanning is fluorodeoxyglucose, a glucose analogue labeled with the ${ }^{18} \mathrm{~F}$ isotope. Fluorodeoxyglucose is used in virtually all scans for oncology and in most cases in neurology, accounting for more than $95 \%$ of all PET scans. However, the images of highest quality are obtained using ${ }^{15} \mathrm{O},{ }^{13} \mathrm{~N}$, and ${ }^{11} \mathrm{C}$ radionuclides [1].

All these isotopes are obtained using nuclear reactions at cyclotrons $[4,5]$. The same isotopes can be obtained using electron accelerators and photonuclear reactions. It should be noted that the isotopes ${ }^{18} \mathrm{~F}$ and ${ }^{11} \mathrm{C}$, obtained on cyclotrons in complex and expensive technological processes $[1,2,6]$, which results in significant increase in the cost of the diagnostics. The use of the ${ }^{12} \mathrm{C}(\gamma, \mathrm{n}){ }^{11} \mathrm{C}$ reaction makes it possible to significantly simplify the process of obtaining a pharmaceuticals using the irradiation of glucose $\left(\mathrm{C}_{6} \mathrm{H}_{12} \mathrm{O}_{6} \cdot \mathrm{H}_{2} \mathrm{O}\right)$ with a beam of bremsstrahlung gamma quanta of an electron accelerator [6 - 8]. A more detailed consideration and optimization of this method for obtaining a diagnostic isotope is of substantial practical interest.

\section{OBTAINING ISOTOPE ${ }^{11} \mathrm{C}$ BY THE PHOTONUCLEAR METHOD}

An experimental study of the photonuclear reaction ${ }^{12} \mathrm{C}(\gamma, \mathrm{n}){ }^{11} \mathrm{C}$ was carried out in a number of works [912]. A generalization of a number of experimental cross sections for the photonuclear reaction ${ }^{12} \mathrm{C}(\gamma, \mathrm{n}){ }^{11} \mathrm{C}$ is shown in Fig. 1, presented in [12]. The energy threshold for the formation of the ${ }^{11} \mathrm{C}$ isotope on the ${ }^{12} \mathrm{C}$ nucleus is 18.72 MeV, the cross section of reaction drops significantly at energies above $35 \mathrm{MeV}$.

Fig. 2 shows the cross section of the photonuclear reaction ${ }^{12} \mathrm{C}(\gamma, \mathrm{n}){ }^{11} \mathrm{C}$, calculated in the TALYS 1.95 code [13].

ISSN 1562-6016. BAHT. 2021. №6(136)

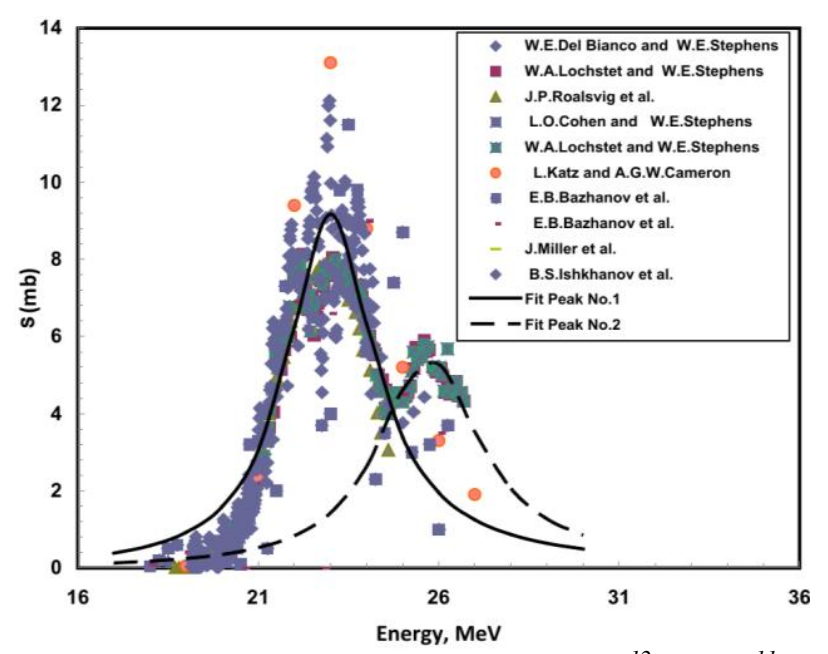

Fig. 1. Photonuclear reaction cross section ${ }^{12} C(\gamma, n){ }^{11} C$

The general view of the cross section is complex, due to the various mechanisms of interaction of photons with the carbon nuclei. In addition, the total of the areas under the cross-sectional curve in the experiment is approximately 3 times greater, which was taken into account in the calculations of the drug activity.

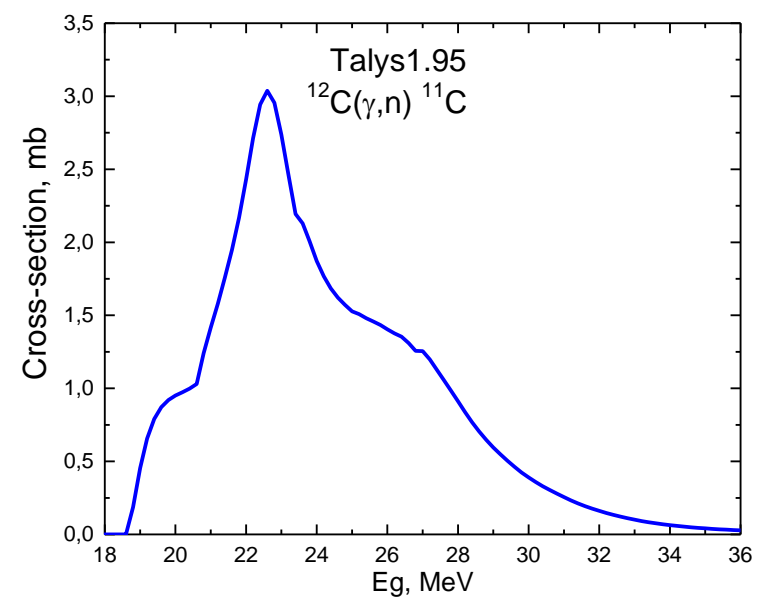

Fig. 2. Cross section for the photonuclear reaction

${ }^{12} C(\gamma, n){ }^{11} C$, calculated in the TALYS 1.95 code

The influence of other channels of reactions that take place in ${ }^{12} \mathrm{C}$ and ${ }^{16} \mathrm{O}$ under the influence of photons can be neglected. 
It was shown in $[6,8]$ that ${ }^{11} \mathrm{C}$ isotope activity equal to $440 \mathrm{MBq}$ was obtained in a sample of glucose with a weight of $4 \mathrm{~g}$ on an LU-40 electron accelerator at an electron beam energy of $36 \mathrm{MeV}$. The accumulated amount of ${ }^{11} \mathrm{C}$ isotope is sufficient for PET diagnostics.

The main problem of the proposed method of obtaining a pharmaceutical product is to eliminate the negative effect of the electron beam. Electrons that passed through the converter can heat the target and change the physical and chemical properties of the irradiated glucose.

The solution to this problem can be found in the application of a magnetic field to prevent the electron beam from hitting the target. Fig. 3 shows a diagram of a device for removing a charged component from the beam of gamma quanta.

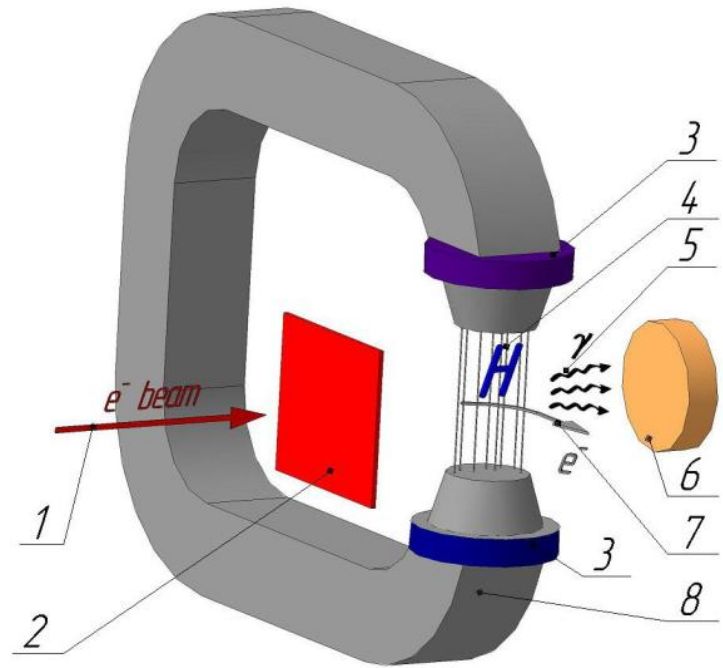

Fig. 3. Diagram of a device for removing a charged component from the beam of gamma quanta:

1 - primary electron beam of the accelerator;

2 - converter, Ta; 3 - permanent magnets ( $\mathrm{NdFeB})$; $4-H$, magnetic field; 5 - gamma quanta from the converter, $\gamma ; 6$-target irradiated with gamma quanta;

7 - secondary charged component; 8 -magnetic core

Similar schemes in various versions are used in the study of photonuclear reactions [14 - 16]. Since our task is to obtain the maximum amount of the isotope, we will try to optimize the proposed scheme taking into account the real parameters of the electron and photon beams.

\section{ESTIMATION OF PHOTON BEAM PARAMETERS}

\subsection{DEPENDENCE OF PHOTON AND ELECTRON BEAMS ON CONVERTER THICKNESS}

Let's consider the parameters of the photon and electron beams that significantly affect the implementation of the proposed photon and electron beams separation scheme.

The electron bremsstrahlung spectra were calculated using the GEANT 4.9.2 program [17] for the real geometry of the experiment, which took into account the spatial and energy distribution of the electron beam. The program code GEANT 4.9.2, PhysList G4LowEnergy makes it possible to carry out calculations with correct consideration of all physical processes for the case of an amorphous target. Tantalum was used as the converter material, which has a number of advantages over other target materials [8].

The calculation was carried out on the assumption that the size of the bending magnet pole is about $150 \mathrm{~mm}$, and thus the minimum distance D from the converter to the target is set to be $150 \mathrm{~mm}$. The diameter of the electron beam at the converter is $5 \mathrm{~mm}$. The electron energy is $35 \mathrm{MeV}$. The target is a cylinder. The target diameter $\mathrm{d}$ is variable from $5 \mathrm{~mm}$ to a limiting value of $\sim 1000 \mathrm{~mm}$, the length $\mathrm{L}$ of the cylinder can also change.

Fig. 4 shows the visualization of the calculation in the GEANT 4.9.2 code. The red lines correspond to a parallel beam of electrons incident on a target-converter of different thicknesses (the cylinder in Fig. 4,a is $0.5 \mathrm{~mm}$ thick, in Fig. $4, \mathrm{~b}$ it is $8 \mathrm{~mm}$ ). A circle with a diameter $\mathrm{d}=60 \mathrm{~mm}$ corresponds to the end face of the irradiated target. Green lines - bremsstrahlung gamma quanta. The red lines behind the converter are scattered electrons. The figure illustrates that the thickness of the converter determines both the number of electrons passing through the converter, which then fall on the target, and the total number of quanta falling on the target.
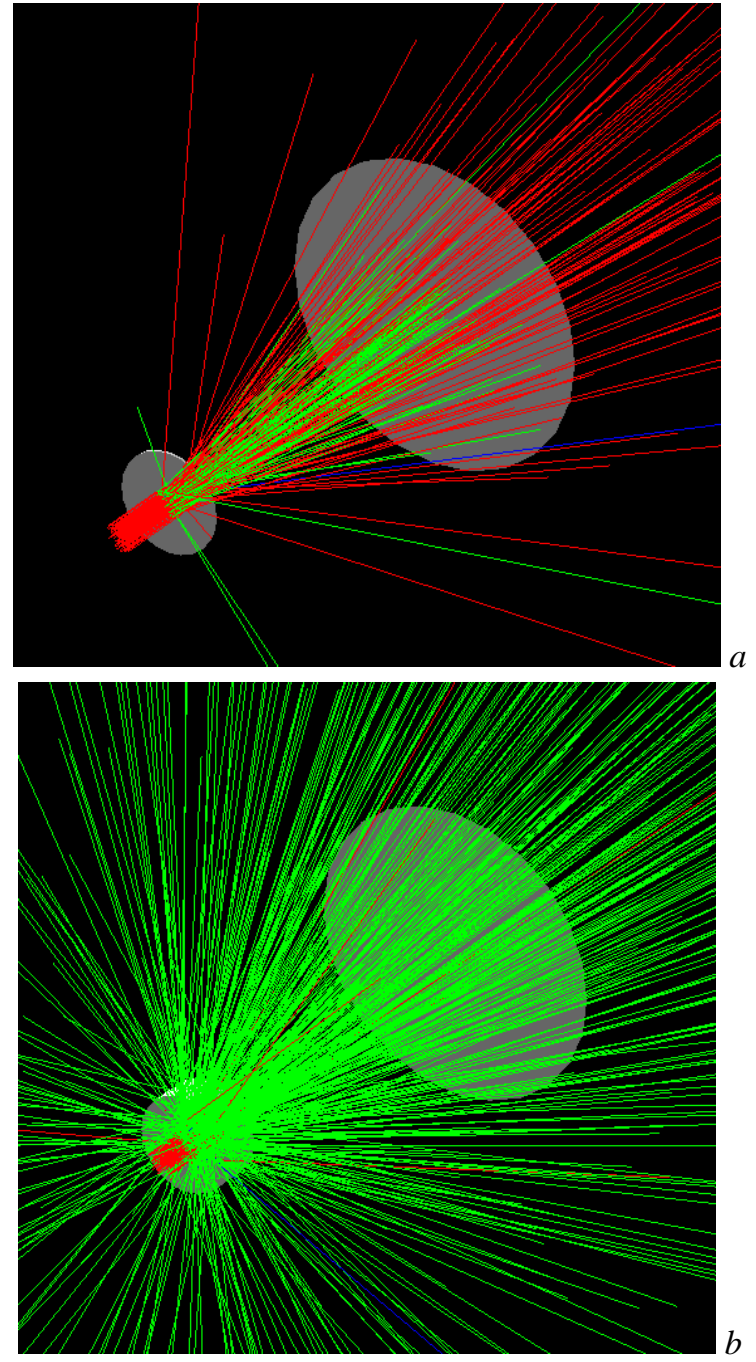

Fig. 4. Visualization of the GEANT code 4.9.2. calculation: 100 electrons $E_{e}=35 \mathrm{MeV}, T a=0.5 \mathrm{~mm}, d=60 \mathrm{~mm}(\mathrm{a})$; 100 electrons $E_{e}=35 \mathrm{MeV}, T a=8 \mathrm{~mm}, d=60 \mathrm{~mm}(b)$ 
Fig. 5 shows the energy spectra of bremsstrahlung gamma quanta for converters of different thicknesses hitting a target $60 \mathrm{~mm}$ in diameter.

Fig. 6 shows the dependence of the number of photons with energies $\mathrm{E}_{\gamma}>18.8 \mathrm{MeV},>22 \mathrm{MeV},>25 \mathrm{MeV}$, incident on a target $60 \mathrm{~mm}$ in diameter, depending on the converter thickness. In addition, the ${ }^{11} \mathrm{C}$ yield was estimated for these conditions using the cross section calculated in the TALYS 1.95 code.

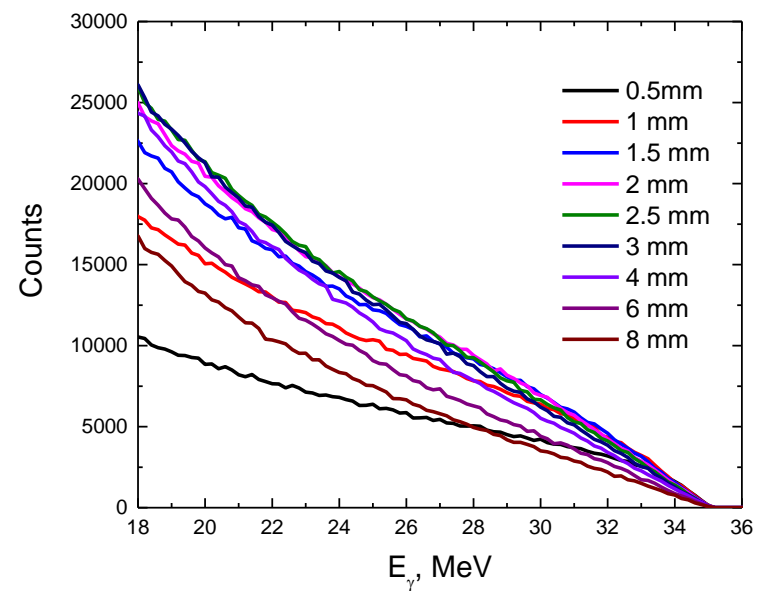

Fig. 5. Bremsstrahlung gamma spectra for different thicknesses of Ta converter. D-distance from converter $150 \mathrm{~mm}$. d-target diameter $60 \mathrm{~mm}$

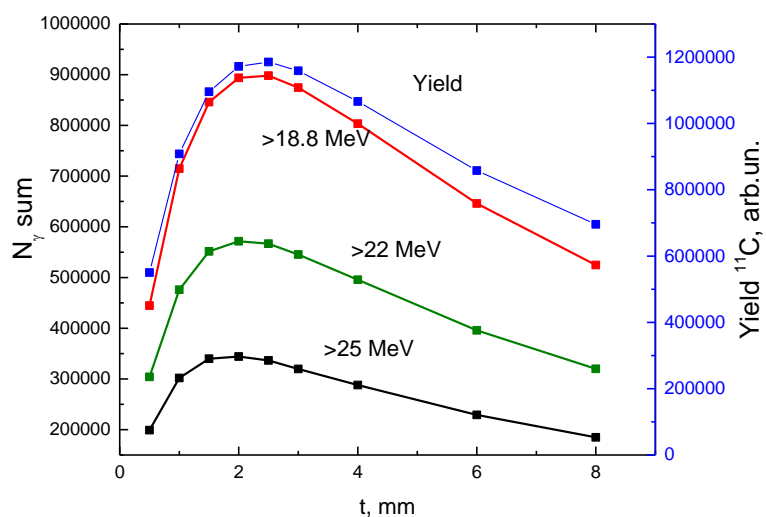

Fig. 6. The flux of photons with energies $>18.8 \mathrm{MeV}$, $>22 \mathrm{MeV},>25 \mathrm{MeV}$, incident on a target $60 \mathrm{~mm}$ in diameter, depending on the thickness of the converter.

${ }^{11} \mathrm{C}$ yield for these conditions using the section calculated in the TALYS 1.95 code

The change in the electron energy in calculations by $\pm 5 \mathrm{MeV}$ had an insignificant effect on the value of the optimal thickness of the converter in this geometry. The figures show that the optimal converter thickness corresponding to the maximum number of quanta and, accordingly, target activation is $\sim 2 \mathrm{~mm}$.

The situation is completely different when the number of electrons falling on the target is estimated. Fig. 7 shows the energy spectra of electrons passing through a Ta converter with a thickness of 0.5 to $8 \mathrm{~mm}$ and hitting a target with a diameter of $60 \mathrm{~mm}$.

From Fig. 7 it can be seen that the number of electrons significantly decreases with an increase in the thickness of the Ta converter. The maximum electron energy after passing through the converter also decreases. However, an increase in the thickness of the con- verter is accompanied not only by a decrease in the number of bremsstrahlung quanta, but also by an increase in the generation of photoneutrons, which makes the use of thick converters problematic.

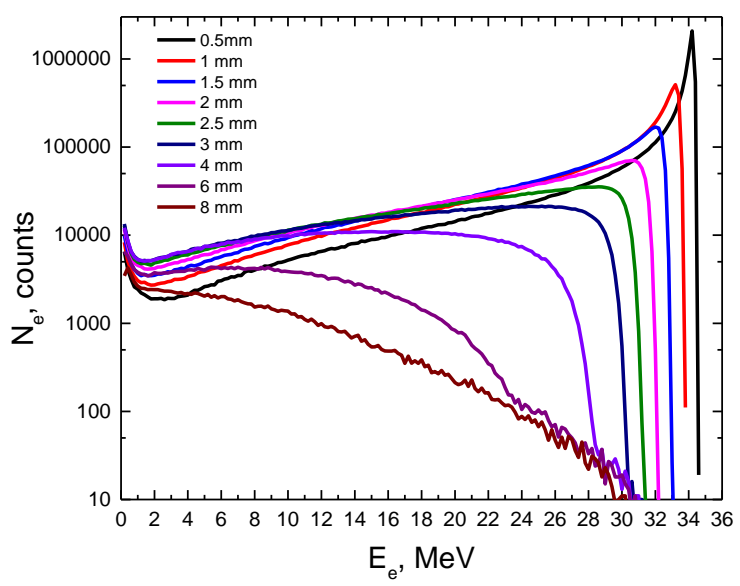

Fig. 7. Energy distributions of electrons passing through a Ta converter with a thickness of 0.5 to $8 \mathrm{~mm}$ and hitting a target $60 \mathrm{~mm}$ in diameter. The distance from the converter to the target is $150 \mathrm{~mm}, E_{e}=35 \mathrm{MeV}$

\subsection{DEPENDENCE OF PHOTON AND ELECTRON BEAMS ON THE TARGET DIAMETER}

Fig. 8 shows the energy spectra of electrons passed through a Ta converter $2 \mathrm{~mm}$ thick and hitting a target with different diameters $d=20 \ldots 1000 \mathrm{~mm} . \mathrm{E}_{\mathrm{e}}=35 \mathrm{MeV}$, the diameter of the electron beam is $5 \mathrm{~mm}$.

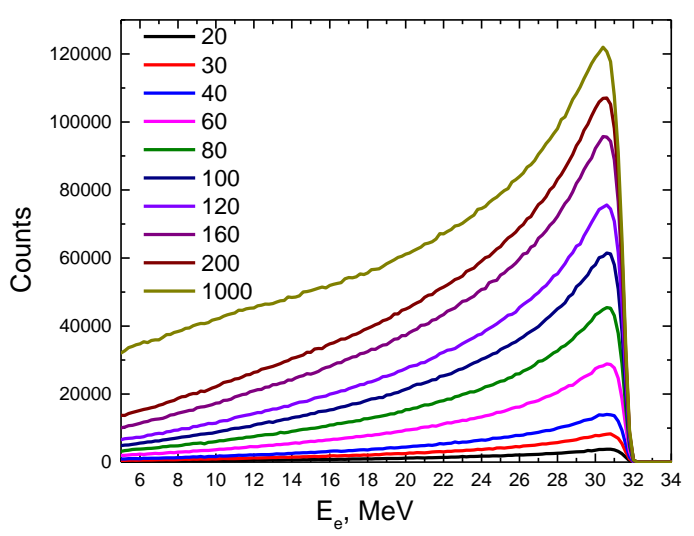

Fig. 8. Energy spectra of electrons passing through a $2 \mathrm{~mm}$ thick Ta converter

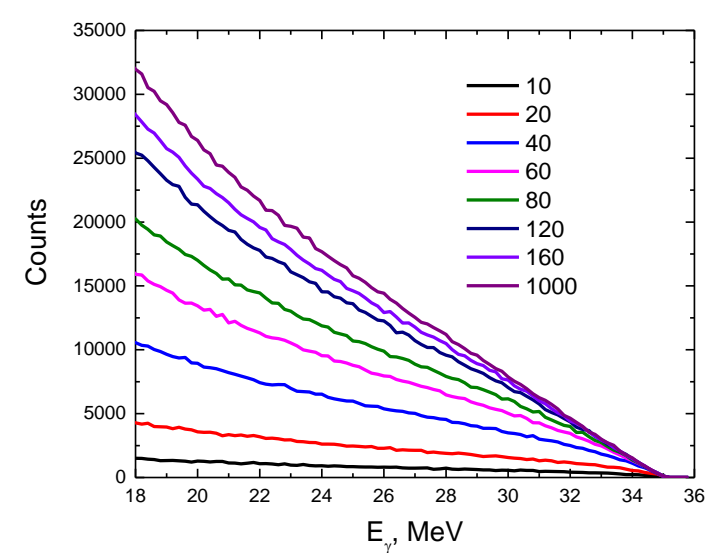

Fig. 9. Energy spectra of bremsstrahlung gamma quanta hitting a target with different diameters $(\mathrm{mm})$ 
Fig. 9 shows the energy spectra of bremsstrahlung gamma quanta falling on a target with different diameters $\mathrm{d}=10 \ldots 1000 \mathrm{~mm}$, located at a distance of $150 \mathrm{~mm}$ from the converter.

It can be seen that in the photon energy range $18 \ldots 35 \mathrm{MeV}$, the flux on a target with a diameter of $40 \mathrm{~mm}$ differs from the flux on a target with a diameter of $1000 \mathrm{~mm}$ by no more than 3 times.

\subsection{ANGULAR DISTRIBUTION OF GAMMA QUANTA AND ELECTRONS}

The angular distribution of gamma quanta and electrons after passing through a $2 \mathrm{~mm}$ Ta converter was calculated using the angle formed by two legs equal to the distance between the converter and the target $(\mathrm{D}=150 \mathrm{~mm})$ and the target radius $(\mathrm{d} / 2, \mathrm{~mm})$. Photons and electrons were summed in the selected energy range and then normalized to the sum of particles for a target of infinite size. Therefore, the value 1 corresponds to the number of electrons (photons) emitted from the converter forward at all angles (front hemisphere). The value 0.5 corresponds to half of the total particle flux and can be used as an estimate of the angular distribution (half-width at half-height of the distribution).

The angular characteristics of the bremsstrahlung beam are shown in Fig. 10. The angular half-width of $175 \mathrm{mrad}$ corresponds to quanta with energies above the reaction threshold.

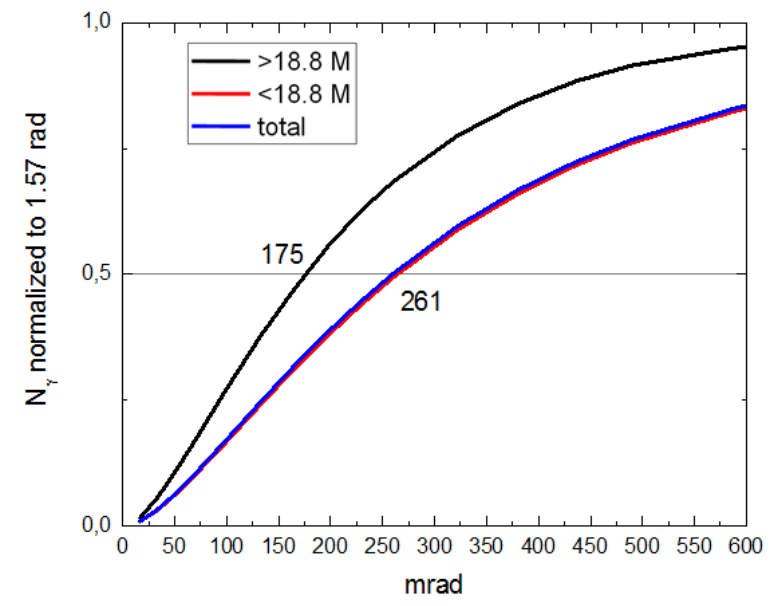

Fig. 10. Angular characteristics of the bremsstrahlung

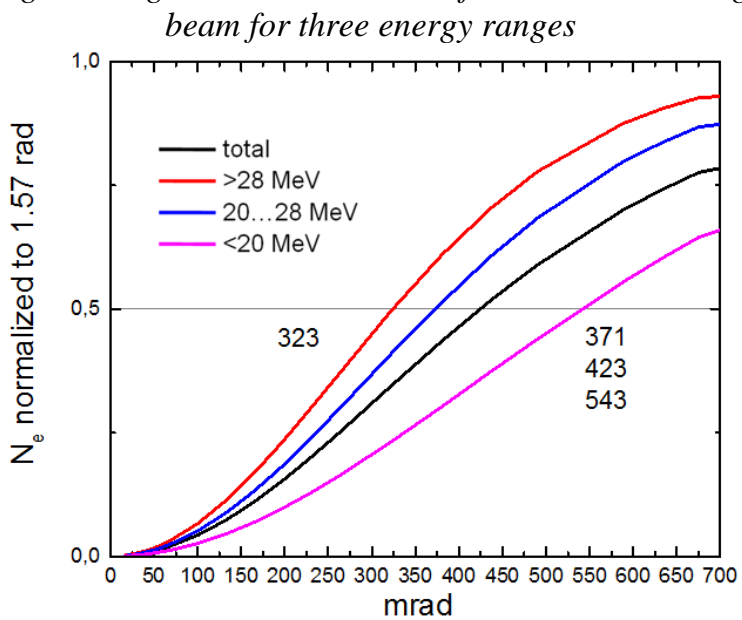

Fig. 11. Angular characteristics of the electron beam passed through the converter
The angular characteristics of the electron beam passed through the converter are shown in Fig. 11. Angular half-width is different for different energy ranges.

As follows from Fig. 10, in order to use half of the maximum possible flux of photons with an energy of more than $18.8 \mathrm{MeV}$ for activation purposes, the diameter of the target located at a distance of $150 \mathrm{~mm}$ from the converter must be at least $53 \mathrm{~mm}$. Moreover, as follows from Fig. 11, an electron beam with energies from $28 \mathrm{MeV}$ to the maximum must be deflected in a magnetic field by an angle equal to the sum of the electron beam divergence angles $323 \mathrm{mrad}\left(18.5^{\circ}\right)$ and the photon beam divergence angle $173 \mathrm{mrad}\left(10^{\circ}\right)$.

\section{SELECTION OF DEFLECTING MAGNET PARAMETERS}

Since an electromagnet deflecting a $30 \mathrm{MeV}$ beam at the required angle with a distance between the poles of $50 \mathrm{~mm}$ will be large and will consume a fairly large amount of electricity, we will consider the possibility of creating such a device based on permanent magnets. The largest fields can be obtained using magnets based on Sm-Co and Nd-Fe-B alloys [18, 19]. When creating real structures, it is necessary to take into account that when these alloys are irradiated with electrons, a change in the magnetic properties of materials occurs, which can lead to a change in the field in magnets [20 - 24]. In Sm-Co alloys irradiated with electrons with energies above $10 \mathrm{MeV}$, a large number of long-lived radioactive isotopes are formed, which limits the use of this material for devices operating at energies above this limit [25].

The largest field value in the gap of a dipole magnet can be obtained by placing a magnetic material (Nd-Fe-B alloy) on the magnet poles. However, the requirement for long-term field stability in the magnet gap results in the magnet design shown in Fig. 12. Magnetic blocks made of Nd-Fe-B alloy are as far as possible from the electron beam and are shielded by rather thick structural elements.

The prototype of this magnet was manufactured and the measured field in the gap is equal to $0.43 \mathrm{~T}$. After completing the design modification, a magnetic field of $0.51 \mathrm{~T}$ was obtained in the gap [18].

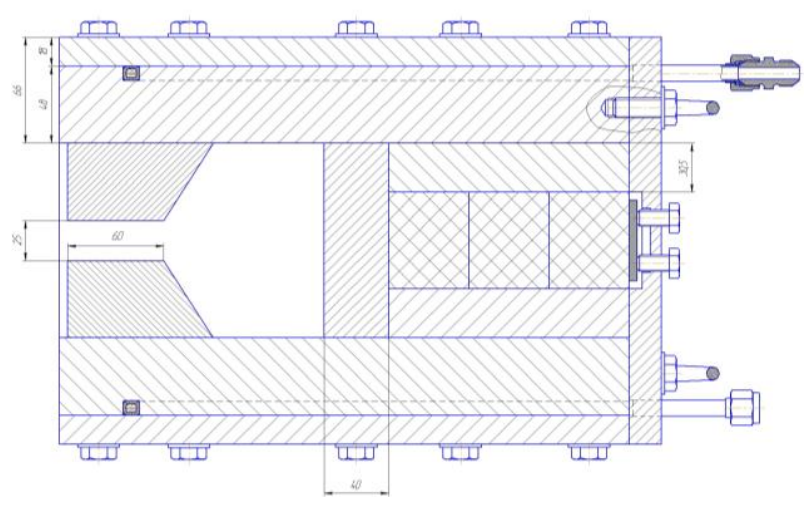

Fig. 12. Cross section of magnet

The presented results of the development of a magnet for the EPOS accelerator allow us to assert that the manufacture of a magnet with a field of $0.5 \mathrm{~T}$ in a gap of $25 \mathrm{~mm}$ with a pole size of $150 \times 60 \mathrm{~mm}$, which is nec- 
essary to separate the photon and electron beams, is a realizable task.

Fig. 13 shows an idealized picture of photon and electron beams for the divergences shown in Fig. 10 and Fig. 11. Blue and gray lines are the boundaries of the photon and electron beams, red are the trajectories of electrons with an energy of $30 \mathrm{MeV}$ in a magnet with a field of $0.5 \mathrm{~T}$ (the radius of the trajectory is $200 \mathrm{~mm}$ ).

The left boundary of the electron trajectories crosses the boundary of the magnet at a distance of $9.36 \mathrm{~mm}$ from the axis of the photon beam. The beam of photons will be collimated vertically by the poles of the magnet. The electron beam will be partially absorbed in the material of the poles, electrons emitted from the magnet in a special dump.

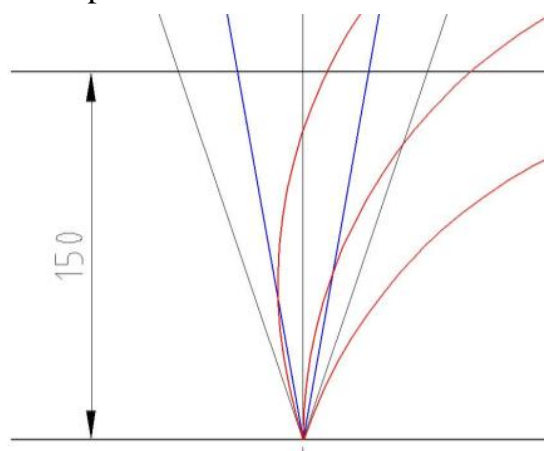

Fig. 13. Particle trajectories in a magnet

\section{CREATION OF ISOTOPE ${ }^{11} \mathrm{C}$ IN A GLUCOSE TARGET}

To assess the activity of irradiated glucose $\left(\mathrm{C}_{6} \mathrm{H}_{12} \mathrm{O}_{6} \cdot \mathrm{H}_{2} \mathrm{O}, 198.16 \mathrm{~g} / \mathrm{mol}\right.$, density $\left.1.562 \mathrm{~g} / \mathrm{cm}^{3}\right)$, placed in a homogeneous photon flux, the following formula was used:

$$
A(t)=N_{C} \cdot F \cdot \sigma \cdot\left(1-\exp \left(-\lambda T_{\text {irr }}\right)\right),
$$

where $\mathrm{N}_{\mathrm{C}}$ is the number of carbon atoms in the target, $\mathrm{F}$ is the integral flux of bremsstrahlung quanta incident on the target, $\sigma$ is the average activation cross section, $\lambda$ is the decay constant, and $\mathrm{T}_{\text {irr }}$ is the irradiation time. The flux of quanta and the activation cross section were calculated using the codes GEANT 4.9.2 and TALYS 1.95.

Work [8] shows that ${ }^{11} \mathrm{C}$ isotope activity of $440 \mathrm{MBq}$ was obtained in a glucose $\mathrm{C}_{6} \mathrm{H}_{12} \mathrm{O}_{6} \cdot \mathrm{H}_{2} \mathrm{O}$ sample weighing $4 \mathrm{~g}$ on LU-40 electron accelerator with electron beam energy $36 \mathrm{MeV}$, electron beam current $6 \mu \mathrm{A}$ using $4 \mathrm{~mm}$ thick tantalum converter and irradiation time of $60 \mathrm{~min}$.

The calculation carried out in the geometry of the experiment [8] gives an activity of $140 \mathrm{MBq} / \mathrm{g}$, which is in agreement with the experimental data.

We have calculated activities for $2 \mathrm{~mm}$ thick tantalum converter, electron energy of $35 \mathrm{MeV}$, convertertarget distance $\mathrm{D}=150 \mathrm{~mm}$ and different target diameters $\mathrm{d}=12,20$, and $30 \mathrm{~mm}$. The target activity for $\mathrm{d}=30 \mathrm{~mm}$ was $10 \mathrm{MBq} / \mathrm{g}$. When the target diameter decreases to $\mathrm{d}=20 \mathrm{~mm}$, the activity is $12 \mathrm{MBq} / \mathrm{g}$, and when $\mathrm{d}=12 \mathrm{~mm}$, the activity is $17 \mathrm{MBq} / \mathrm{g}$. Thus, under the proposed conditions, even at low electron beam currents $(6 \mu \mathrm{A})$ in a volume of $10 \mathrm{ml}(15.6 \mathrm{~g})$, activity of up to $265 \mathrm{MBq}$ can be obtained.

\section{CONCLUSIONS}

The parameters of the bremsstrahlung and the electron beam scattered in the converter was investigated and optimized. It is shown that a permanent magnet fabricated using an Nd-Fe-B alloy will make it possible to spatially separate the photon and electronic components of the bremsstrahlung of an electron beam with an energy of $35 \mathrm{MeV}$. The photon beam thus obtained, purified from electrons, allows the production of the pharmaceutical product "Glucose ${ }^{11} \mathrm{C}$ " with activity of $\sim 500 \mathrm{MBq} / \mathrm{g}$ and electron beam current of $200 \mu \mathrm{A}$.

\section{REFERENCES}

1. Kristen M. Waterstram-Rich, David Gilmore. Nuclear Medicine and PET/CT. E-Book: Technology and Techniques, eighth edition. 2017, $696 \mathrm{p}$.

2. Radioisotopes in Medicine, https://www.worldnuclear.org/information-library/non-power-nuclearapplications/radioisotopes-research/radioisotopes-inmedicine.aspx, Updated May 2020.

3. F.T. Tárkányi, A.V. Ignatyuk, et al. Recommended nuclear data for medical radioisotope production diagnostic positron emitters // Journal of Radioanalytical and Nuclear Chemistry. 2019, v. 319, p. 533-666.

4. A.P. Chernyaeva, P.Yu. Borschegovskaya, A.A. Nikolaeva, S.M. Varzar, V.T. Samosadniy, G.A. Krusanov. Radiation technology in medicine: Part 2. Using isotopes in nuclear medicine // Moscow University Physics Bulletin. 2016, v. 71, p. 339348.

5. Medical Radioisotopes Production, https://wwwnds.iaea.org/relnsd/vcharthtml/MEDVChart.html

6. V. Voronko, R. Dronov, B. Shramenko, I. Beloziorov, I. Girka. Possibilities of obtaining radiopharmaceuticals "Glucose, ${ }^{11} \mathrm{C}$ " and "Ethanol, ${ }^{11} \mathrm{C}$ " for pet tomography on accelerators of NSC KIPT // Ukrainian Radiological Journal. 2019, t. XXVII, v. 1.

7. A.M. Dovbnya, B.I. Shramenko. Method of obtaining radiopharmaceutical "Glucose, ${ }^{11} \mathrm{C}$ " for PET tomography: Patent of Ukraine № 28463 / 3A / 18 from 27.11.2018.

8. A.N. Dovbnya, R.N. Dronov, et al. Production of ${ }^{11} \mathrm{C}$ and ${ }^{18} \mathrm{~F}$ isotopes. Getting the "Glucose, ${ }^{11} \mathrm{C}$ " radiopharmaceutical // East European Journal of Physics (EEJP). 2018, v. 5, № 4, p. 77-86.

9. B.C. Cook, J.E.E. Baglin, J.N. Bradford, and J.E. Griffin. $C^{12}(\gamma, n) C^{11}$ Cross Section to $65 \mathrm{MeV} / /$ Phys. Rev. 1966, v. 143, p. 724-729.

10. S.C. Fultz, J.T. Caldwell, B. Berman, R. Bralett and R. Harvey. Photoneutron Cross Sections for $\mathrm{C}^{12}$ and $\mathrm{Al}^{27} / /$ Phys. Rev. 1966, v. 143, p. 790-796.

11. A.V. Varlamov, V.V. Varlamov, D.S. Rudenko, M.E. Stepanov // Atlas of Giant Dipole Resonances. January 1999, $321 \mathrm{p}$.

12. Ahmed Abdul-Razzaq Selman. Systematics of (Gamma-N) Reaction with Light Nuclei-Part I // International Journal of Scientific and Engineering Research, December-2013, v. 4, issue 12, p. 20212028. 
13. A. Koning and D. Rochman, Nucl. Data Sheets 113 (2012) 2841, TALYS - based evaluated nuclear data library. https://tendl.web.psi.ch/tendl2019/tendl2019.html.

14. L.M. Young. Photoneutron Cross Sections and Spectra from Monoenergetic Photons on Yttrium, Praseodimium, Lead, and Bismuth in the Giant Resonance. Ph.D. Thesis, University of Illinois, USA, 1972.

15. L.S. Cardman. Photon Tagging. Present Practice and Future Prospects: Preprint P/83/12/168, University of Illinois at Urbana-Champaign, 1983.

16. D. Burdeinyi, J. Brudvik, V. Ganenko, et al. Measurement of $(\gamma, \mathrm{p})$ reactions with $\Delta \mathrm{E}-\mathrm{E}$ telescope at MAX-LAB facility // Problems of Atomic Science and Technology. Series "Nuclear Physics Investigations”. 2015, № 3, p. 49-64.

17. S. Agostinelli et al. Geant4 a simulation toolkit // Nuclear Instruments and Methods in Physics Research Section A: Accelerators, Spectrometers, Detectors and Associated Equipment. 1 July 2003, v. 506, issue 3 , p. $250-303$.

18. https://en.wikipedia.org/wiki/Neodymium_magnet.

19. https://en.wikipedia.org/wiki/Samarium\%E2\%80\%9 3cobalt_magnet.
20. V.A. Bovda, A.M. Bovda, I.S. Guk, A.N. Dovdnya, A.Yu. Zelinsky, S.G. Kononenko, V.N. Lyashchenko, A.O. Mytsykov, L.V. Onishchenko. Dipole magnets for the technological electron accelerators // Proceedings of IPAC2018. Vancouver, BC, Canada, THPAL043.

21. A.M. Bovda et al. Magnetic properties of $\mathrm{Sm}_{2} \mathrm{Co}_{17}$ magnets under $10 \mathrm{MeV}$ electron beam // Problems of Atomic Science and Technology. Series "Nuclear Physics Investigations”. 2017, № 6, p. 162-166.

22. V.A. Bovda et al. Magnetic field losses in Nd-Fe-B magnets under 10mev electron irradiation // Problems of Atomic Science and Technology. Series “Nuclear Physics Investigations”. 2017, № 3, p. 9094.

23. N. Simos et al. Demagnetization of $\mathrm{Nd} 2 \mathrm{Fe} 14 \mathrm{~B}$, $\mathrm{Pr}_{2} \mathrm{Fe}_{14} \mathrm{~B}$, and $\mathrm{Sm}_{2} \mathrm{Co}_{17}$ Permanent Magnets in Spallation Irradiation Fields // IEEE Transactions on Magnetics. 2018, v. 54, p. 1-10.

24. V.A. Bovda et al. Magnetic properties of Nd-Fe-B magnets under electron beam irradiation with the energy $23 \mathrm{MeV} / /$ Problems of Atomic Science and Technology. 2020, № 3, p. 23-27.

25. A.M. Bovda, I.S. Guk, A.N. Dovbnya, S.G. Kononenko, V.N. Lyashchenko, A.O. Mytsykov. Dipole magnet with a constant field for the accelerator "EPOS" // Problems of Atomic Science and Technology. Series "Nuclear Physics Investigations". 2015, № 6, p. 1317.

Article received 04.10.2021

\section{ОПТИМИЗАЦИЯ НАРАБОТКИ ФАРМПРЕПАРАТА "ГЛЮКОЗА ${ }^{11} \mathrm{C}$ " НА ПУЧКЕ УСКОРИТЕЛЯ ЭЛЕКТРОНОВ}

\section{И.С. Гук, Р.Н. Дронов, А.С. Деев, Б.И. Шраменко}

Рассмотрен процесс получения фармпрепарата “Глюкоза ${ }^{11} \mathrm{C}$ ” с помощью фотоядерной реакции ${ }^{12} \mathrm{C}(\gamma, \mathrm{n}){ }^{11} \mathrm{C}$. Исследованы и оптимизированы параметры тормозного излучения и рассеянного в конверторе электронного пучка. Для очистки фотонного пучка от электронов предлагается использовать магнит с постоянным полем. Предложена конструкция магнита, позволяющая получить поле 0,5 Тл в зазоре 25 мм. Проведена оценка наработки изотопа ${ }^{11} \mathrm{C}$ в мишени из глюкозы.

\section{ОПТИМІЗАЦІЯ НАПРАЦЮВАННЯ ФАРМПРЕПАРАТУ "ГЛЮКОЗА ${ }^{11}$ " " НА ПУЧКУ ПРИСКОРЮВАЧА ЕЛЕКТРОНІВ}

\section{І.С. Гук, Р.М. Дронов, О.С. Деєв, Б.І. Шраменко}

Розглянуто процес одержання фармпрепарату “Глюкоза ${ }^{11} \mathrm{C}$ ” за допомогою фотоядерної реакції ${ }^{12} \mathrm{C}(\gamma, \mathrm{n}){ }^{11} \mathrm{C}$. Досліджені і оптимізовані параметри гальмового випромінювання і розсіяного в конверторі електронного пучка. Для очищення фотонного пучка від електронів пропонується використовувати магніт 3 постійним полем. Запропоновано конструкцію магніту, що дозволяє одержати поле 0,5 Тл у зазорі 25 мм. Проведено оцінку напрацювання ізотопу ${ }^{11} \mathrm{C}$ у мішені з глюкози. 